\title{
REALISASI DAN DESAIN DINAMIKA BERJALAN NAIK DIATAS TANGGA PADA 33 DOF HUMANOID ROBOT
}

\author{
Wulandari Puspita Sari1, R. Sanggar Dewanto², Dadet Pramadihanto ${ }^{3}$ \\ 1,2,3 Politeknik Elektronika Negeri Surabaya \\ Kampus PENS Jalan Raya ITS Sukolilo, Surabaya, 60111 \\ Email: wulandari.elektro28@gmail.com, \{sanggar, dadet\}@pens.ac.id
}

\begin{abstract}
This paper presents a balance control for humanoid robot for walking on the stair. Kinematics, dynamics, and control system are the complex problems for humanoid robot especially in walking through the stair. The goal of this paper is to implement the control methods for the robot to be able to walk through the stair. The complexities are influenced by the number of joint movements of 33 degree of freedom (DoF) resulting flexible movements. This movement patterns in walking on the stair considers the height and the width of the stair by using the feedback sensors and the proportional-integral (PI) controller. Walking transition from single phase to double phase is needed to conduct the smooth transition. To solve that problem, an integrated motion and controller are divided to two conditions: working motion in the offline planning and working motion in the online implementation. Vertical movement and the step-length movement are needed due to the additional movements are required for walking on the stair. That is why, PI controller is used to achieve the balance condition. Each controller is used in detail with the results of experiments and simultions. The kinematics approach for simulation has 100\% successful rate and the realtime experiments have 93\% of error. The effectivity and results of the proposed algorithm for humanoid robot are verified by the experiments to walk on the stair.
\end{abstract}

Keywords: dynamic, kinematic, balance control, humanoid robot

\begin{abstract}
Abstrak
Makalah ini menyajikan kontrol keseimbangan untuk robot humanoid dalam berjalan di atas tangga. Kinematika, dinamika, dan sistem kendali merupakan masalah kompleks pada robot humanoid khususnya untuk berjalan melewati tangga. Tujuan akhir makalah ini adalah penerapan metode kontrol pada robot humanoid agar robot dapat berjalan di atas tangga. Kompleksitas pada robot dipengaruhi oleh banyaknya penggerak sebesar 33 derajat kebebasan (DoF) sehingga menghasilkan gerakan yang fleksibel. Pola gerakan ketika berjalan diatas tangga ini mempertimbangkan tinggi tangga dan lebar tangga dengan adanya umpan balik pada sensor dan system kendali keseimbangan menggunakan proporsional-integral (PI) kontroler. Transisi berjalan dari fase dukungan tunggal ke fase dukungan ganda diperlukan untuk kelancaran siklus transisi. Untuk menyelesaikan masalah tersebut, sebuah gerakan terintegrasi dan pengontrol dibagi menjadi dua kondisi: gerakan bekerja pada perencanaan offline dan pengontrol bekerja yang berjalan online. Hal ini dikarenakan kebutuhan tambahan gerakan vertikal pada tinggi tangga dan panjang langkah ketika menaiki tangga. Oleh karena itu, kontroler PI digunakan untuk mencapai kondisi keseimbangan. Setiap pengendali ditangani secara detail dengan hasil eksperimen dan simulasi. Pendekatan Kinematika untuk simulasi memiliki hasil yang
\end{abstract}


baik berdasarkan percobaan simulasi $100 \%$ dan percobaan secara langsung dengan robot memiliki error 93\%. Efektivitas dan kinerja dari algoritma kontrol yang diusulkan diverifikasi melalui percobaan naik tangga pada humanoid robot.

Kata kunci: dinamika, kinematika, kendali keseimbangan, robot humanoid

\section{PENDAHULUAN}

Robot humanoid adalah robot yang memiliki bentuk seperti manusia. Desain humanoid mampu menduplikasi aktivitas seperti manusia [1]. Robot humanoid memiliki 2 kaki, 2 tangan. Faktor utama penstabil robot humanoid seluruh tubuh adalah hal yang penting. Sistem yang kokoh pada robot humanoid yaitu robot yang dapat melakukan penugasan di berbagai permukaan, seperti biasanya berjalan di tanah, tangga, dan permukaan lainnya. Ada banyak masalah lintasan dinamis dan kestabilan berjalan di bidang yang tidak rata. Penggabungan pola pada siklus dinamis berjalan adalah masalah yang kompleks dan rumit. Seperti pada robot K.Mei yang membangun sebuah pola gerakan menari tradisonal [2]. Ada berbagai metode yang digunakan, misalnya: menggunakan gerakan yang ditangkap langsung dari manusia dan gerakan berkelanjutan berdasarkan lintasan yang dihasilkan oleh pembangkitan pola tersebut [3].

Berbagai metode di tawarkan pada robot yang memiliki struktur komplek seperti robot humanoid. Dalam lintasan kaki dihitung dengan metode komputasi cerdas dan analisis kendala melangkah tangga. Kekhawatiran umum mengurangi kesalahan timbulnya titik momen nol yang mempengaruhi gerakan vertikal dan horizontal. Sangat pentingnya stabilitas robot berjalan dinamis yang memiliki percepatan linier dan sudut [4]. Model yang disederhanakan menggunakan pendekatan pendulum terbalik. Ada dua pendekatan untuk pemodelan robot dua kaki: model tubuh bagian atas dan model tubuh bagian bawah (kaki). Informasi detail dari model yang tepat dari parameter dinamis robot akan memepengaruhi algoritma yang di bangun. Gerakan berjalan secara 3D memastikan dinamika dengan menggunakan kendali non-linier dengan pendekatan MPC yang efisien, dan berhasil selama berjalan di medan yang miring dan berjalan di tanah [5]. Skema untuk perencanaan lintasan berjalan di tangga terdapat beberapa parameter yang harus dipenuhi. Perpindahan massa CoG dan ZMP terbatas untuk gerakan tertentu yang menyebabkan gerakan akan berdampak pada gerakan yang lain. Para penulis menyebarkan berbagai lintasan dalam posisi ganda dan tunggal. Sementara tinggi CoM konstan diasumsikan dalam posisi tunggal, cubic polynomial digunakan untuk fase dukungan ganda. Interpolasi ini memungkinkan transisi ke ketinggian CoM yang berbeda [6]. Para penulis tidak semua memberikan alasan untuk pendekatan mereka tetapi mereka menunjukkan dalam simulasi kemampuan untuk berjalan stabil di medan yang tidak rata. Kendala kinematik pada batasan mekanik yang bisa dihindari oleh penulis. Selain itu, publikasi terbaru bahkan menunjukkan pengaruh stabilisasi diri dengan menerapkan lintasan tinggi badan yang dirancang dengan baik [7]. Baru-baru ini, kerangka kerja optimasi telah disajikan yang menghasilkan gerakan robot untuk urutan berjalan sambil mengambil dinamika serta kendala kinematik dengan pendekatan pendulum terbalik untuk stabilisasi [8]. Pendekatan-pendekatan ini adalah metode 
murni murni atau masih membutuhkan waktu perhitungan yang lama pada awalnya untuk gerakan dasar dengan menggabungkan bagian atas tubuh atau bawah tubuh [9]. Dalam penelitian ini, pendekatan cubic polynomial digunakan untuk merancang gerakan, dan fokus pada gaya vertikal dan horizontal untuk menghasilkan pola yang optimal [10]. Strategi untuk berjalan di tangga dengan melacak pergerakan CoP dan CoM sistem. Titik ini berlaku bahkan kontak jari kaki terletak pada poligon dukungan. Pola berjalan umumnya dibagi menjadi dua kondisi: kondisi pertama adalah kondisi SSP (Singgle Support Phase) dari satu ayunan kaki. Kondisi kedua adalah kondisi DSP (Double Support Phase) dua kaki di tanah.

Ketinggian tangga akan mempengaruhi keseimbangan pada seluruh tubuh robot [11]. Dengan adanya kontrol yang dilakukan dengan pendekatan pendulum terbalik. Maka perpindahan massa setiap gerakan dinamis untuk menghitung distribusi massa keseluruh tubuh dengan memeperhatikan area stabilitas pada robot tersebut. Sebagai konsekuensi dari kestabilan maka makalah ini akan membahas mengenai model dinamis robot berserta kontrol yang di gunakan untuk berjalan diatas tangga yang dibangun dengan simulasi dan diverifikasi dengan percobaan.

\section{METODOLOGI PENELITIAN \\ 2.1 Kinematika}

Gerakan dari rantai kinematik yang merupakan robot atau karakter animasi dimodelkan oleh persamaan kinematika rantai. Persamaan menentukan konfigurasi rantai dalam hal parameter bersama. Sebagai contoh, formula kinematika terbalik memungkinkan perhitungan parameter bersama yang posisi robot lengan digunakan untuk mengambil salah satu bagian. Formula yang sama dapat digunakan untuk menentuka posisi dari kerangka dari sebuah karakter animasi yang bergerak dengan cara tertentu [12].

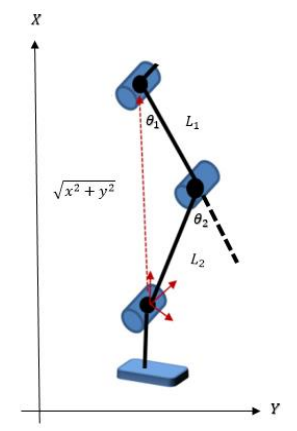

Gambar 1. Solusi kinematik pendekatan geometri pada kaki

Untuk mencari kinematika terbalik pada 2 Link Planar manipulator adalah dengan mencari sudut yang paling dekat dengan end of efector (EoE). Pada Gambar 1. diatas, yang paling dekat dengan EoE adalah sudut $\theta_{2}$. Maka dapat digunakan metode solusi geometris segitiga seperti dibawah ini:

$x^{2}+y^{2}=L_{1}^{2}+L_{2}^{2}-2 L_{1} L_{2} \cos \left(180-\theta_{2}\right)$ 


$$
\begin{aligned}
& x^{2}+y^{2}=L_{1}^{2}+L_{2}^{2}-2 L_{1} L_{2} \cos \left(\theta_{2}\right) \\
& \theta_{2}=\cos ^{-1}\left(\frac{x^{2}+y^{2}-L_{1}^{2}-L_{1}^{2}}{2 L_{1} L_{2}}\right)
\end{aligned}
$$

Setelah mendapatkan $\theta_{2}$, maka dapat dicari $\theta_{1}$ dengan menggunakan solusi metode aljabar. Diketahui posisi end of efector (EoE) yaitu $(\mathrm{x}, \mathrm{y})$ yang dijabarkan dibawah ini.

$$
\begin{aligned}
& x=x_{1}+x_{2} \\
& y=y_{1}+y_{2}
\end{aligned}
$$

Dimana:

$$
\begin{aligned}
& x_{1}=L_{1} \cos \theta_{1} \\
& y_{1}=L_{1} \sin \theta_{1} \\
& x_{2}=L_{2} \cos \left(\theta_{i 1}+\theta_{2}\right) \\
& y_{2}=L_{2} \sin \left(\theta_{1}+\theta_{2}\right)
\end{aligned}
$$

Sehingga jika persamaan (3), (4), (5), dan (6) diatas dimasukkan kedalam persamaan (1) dan (2), maka akan menjadi.

$$
\begin{aligned}
& x=L_{1} \cos \theta_{1}+L_{2} \cos \left(\theta_{1}+\theta_{2}\right) \\
& y=L_{1} \sin \theta_{1}+L_{2} \sin \left(\theta_{1}+\theta_{2}\right)
\end{aligned}
$$

Untuk mendapatkan $\theta_{1}$ perlu dilakukan manipulasi persamaan dengan menganggap komponen selain $\theta_{1}$ sebagai konstanta. Sehingga didapatkan persamaan baru untuk $\mathrm{x}$ adalah :

$$
\begin{aligned}
& x=L_{1} \cos \theta_{1}+L_{2} \cos \left(\theta_{1}+\theta_{2}\right) \\
& x=L_{1} \cos \theta_{1}+L_{2}\left(\cos \theta_{1} \cos \theta_{2}-\sin \theta_{1} \sin \theta_{2}\right) \\
& x=\cos \theta_{1}\left(L_{1}+L_{2} \cos \theta_{2}\right)-\sin \theta_{1}\left(L_{2} \sin \theta_{2}\right) \\
& x=\cos \theta_{1} A-\sin \theta_{1} B
\end{aligned}
$$

Dan untuk y adalah :

$$
\begin{aligned}
& y=L_{1} \sin \theta_{1}+L_{2} \sin \left(\theta_{1}+\theta_{2}\right) \\
& y=L_{1} \sin \theta_{1}+L_{2}\left(\cos \theta_{1} \sin \theta_{2}+\sin \theta_{1} \cos \theta_{2}\right) \\
& y=\cos \theta_{1}\left(L_{2} \sin \theta_{2}\right)-\sin \theta_{1}\left(L_{1}+L_{2} \cos \theta_{2}\right) \\
& y=\cos \theta_{1} B-\sin \theta_{1} A
\end{aligned}
$$

Pada Gambar 2. dapat dilihat misalkan A dan B adalah sisi - sisi segitiga siku - siku dengan sisi miring $\mathrm{R}$, maka didapat.

$$
\begin{aligned}
& A=R \quad \cos \theta_{\gamma} \\
& B=R \sin \theta_{y} \\
& \theta_{\sigma}=\operatorname{atan} 2\left(\sin \theta_{\sigma}, \cos \theta_{\sigma}\right)
\end{aligned}
$$


Sehingga jika disubtitusikan kedalam persamaan (13) dan (15) akan menjadi

$$
\begin{aligned}
& \begin{aligned}
x & =R \quad \cos \theta_{\sigma} \cos \theta_{1}-R \quad \sin \theta_{\sigma} \sin \theta_{1} \\
& =R \quad \cos \left(\theta_{\sigma}+\theta_{1}\right)
\end{aligned} \\
& \begin{aligned}
y & =R \quad \sin \theta_{\sigma} \cos \theta_{1}-R \quad \cos \theta_{\sigma} \sin \theta_{1} \\
& =R \quad \sin \left(\theta_{\sigma}+\theta_{1}\right)
\end{aligned} \\
& \tan \left(\theta_{\sigma}+\theta_{1}\right)=\frac{\sin \left(\theta_{\sigma}+\theta_{1}\right)}{\cos \left(\theta_{\sigma}+\theta_{1}\right)}=\frac{y_{/ R_{D P}}}{x_{/ R_{D P}}}=\frac{y}{x} \\
& \theta_{\sigma}+\theta_{1}=\tan ^{-1}\left(\frac{y}{x}\right)=\operatorname{atan} 2(y, x) \\
& \theta_{1}=\operatorname{atan} 2(y, x)-\theta_{\sigma} \\
& \theta_{1}=\operatorname{atan} 2(y, x)-\operatorname{atan} 2\left(\sin \theta_{\sigma}, \cos \theta_{\sigma}\right) \\
& \theta_{1}=\operatorname{atan} 2(y, x)-\operatorname{atan} 2\left(\frac{B}{R}, \frac{A}{R}\right) \\
& \theta_{1}=\operatorname{atan} 2(y, x)-\operatorname{atan} 2(B, R) \\
& \theta_{1}=\operatorname{atan} 2(y, x)-\operatorname{atan} 2\left(L_{2} \sin \theta_{2}, L_{1}+L_{2} \cos \theta_{2}\right)
\end{aligned}
$$

Sehingga didapatkanlah nilai dari $\theta_{2}$ dan $\theta_{1}$ yang berada pada persamaan (29) dan (30) yaitu :

$$
\begin{aligned}
& \theta_{2}=\cos ^{-1}\left(\frac{x^{2}+y^{2}-L_{1}{ }^{3}-L_{2}{ }^{3}}{2 L_{1} L_{2}}\right) \\
& \theta_{1}=\operatorname{atan} 2(y, x)-\operatorname{atan} 2\left(L_{2} \sin \theta_{2}, L_{1}+L_{2} \cos \theta_{2}\right)
\end{aligned}
$$

Bisa juga mencari $\theta_{1}$ dengan menggunakan metode solusi geometris dimana.

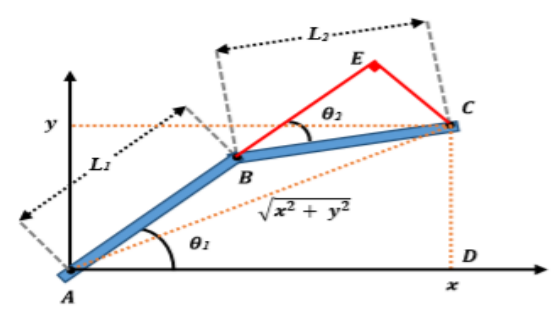

Gambar 2. 2-Link Planar Manipulator (pendekatan model kaki)

Dalam aturan sinus berlaku:

$$
\frac{\sin \theta_{\alpha}}{a}=\frac{\sin \theta_{\beta}}{b}=\frac{\sin \theta_{Y}}{c}
$$

Dari segitiga ACD diperoleh:

$$
\begin{aligned}
& \sin \left(\theta_{1}+\theta_{\alpha}\right)=\frac{y}{\sqrt{x^{2}+y^{2}}} \\
& \theta_{1}+\theta_{\alpha}=\sin ^{-1}\left(\frac{y}{\sqrt{x^{2}+y^{2}}}\right)
\end{aligned}
$$


$\theta_{1}=\sin ^{-1}\left(\frac{y}{\sqrt{x^{2}+y^{2}}}\right)-\theta_{\alpha}$

Dari segitiga ABC didapatkan beberapa persamaan segitiga sebagai berikut:

$\theta_{\alpha}=\operatorname{atan} 2\left(\frac{\sin \theta_{\alpha}}{\cos \theta_{\alpha}}\right)$

$\frac{\sin \theta_{\alpha}}{L_{2}}=\frac{\sin \left(180-\theta_{2}\right)}{\sqrt{x^{2}+y^{2}}}=\frac{\sin \theta_{2}}{\sqrt{x^{2}+y^{2}}}$

$\sin \theta_{\alpha}=\frac{L_{2} \sin \theta_{2}}{\sqrt{x^{2}+y^{2}}}$

Untuk $\cos \alpha$ dapat dicari dari segitiga - segitiga ACE dan BCE, dengan panjang sisi A-B-E adalah $L_{1}+L_{2} \cos \theta 2$ sehingga:

$\cos \theta_{\alpha}=\frac{L_{1}+L_{2} \cos \theta_{2}}{\sqrt{x^{2}+y^{2}}}$

Setelah itu dapat dimasukkan ke dalam persamaan (35) untuk mencari nilai $\alpha$ yang sebenarnya:

$$
\begin{aligned}
\theta_{\alpha}= & \operatorname{atan} 2\left(\frac{\sin \theta_{\alpha}}{\cos \theta_{\alpha}}\right)=\operatorname{atan} 2\left(\frac{\frac{L_{2} \sin \theta_{2}}{\sqrt{x^{2}+y^{2}}}}{\frac{L_{1}+L_{2} \cos \theta_{2}}{\sqrt{x^{2}+y^{2}}}}\right) \\
= & \operatorname{atan} 2\left(\frac{L_{2} \sin \theta_{\Omega s}}{L_{1}+L_{2} \cos \theta_{m}}\right)
\end{aligned}
$$

Setelah mendapatkan nilai $\alpha$, maka persamaan (38) dapat terselesaikan dengan memasukkan nilai $\alpha$ langsung.

$$
\begin{aligned}
& \theta_{1}=\sin ^{-1}\left(\frac{y}{\sqrt{x^{2}+y^{2}}}\right)-\theta_{\alpha} \\
& \theta_{1}=\sin ^{-1}\left(\frac{y}{\sqrt{x^{2}+y^{2}}}\right)-\operatorname{atan} 2\left(\frac{L_{2} \sin \theta_{2}}{L_{1}+L_{2} \cos \theta_{2}}\right) \\
& \theta_{1}=\operatorname{atan} 2(y, x)-\operatorname{atan} 2\left(L_{2} \sin \theta_{2}, L_{1}+L_{2} \cos \theta_{2}\right)
\end{aligned}
$$

Dari hasil kedua solusi aljabar maupun solusi geometris memiliki solusi jawaban yang sama. Solusi diatas berada pada kuadran pertama (1) yang dapat diketahui karena sama - sama mengandung atan $2(y, x)$.

\subsection{Dinamika}

Gerakan robot berkaki dua memiliki kerumitan tersendiri dalam gerakan yan dinamis. Manusia yang sehat dapat menjaga keseimbangan saat berjalan karena keterampilan yang diperoleh dengan belajar [13]. Di bawah keterampilan seperti itu, komponen kekuatan / momen yang terdapat pada fase kaki satu, atau pada kedua kaki. Bab ini membahas model-model robot non-manusiawi yang dipasangkan secara manusiawi. Model-model tersebut digunakan dalam analisis dan kontrol model berbasis 

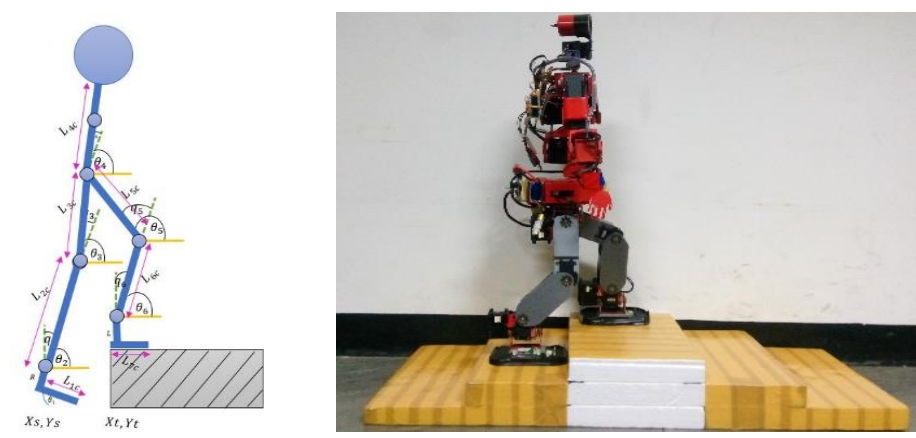

Gambar 3. Robot model 7 link

Pemodelan dinamis dari robot humanoid disederhanakan menggunakan persamaan lagrange [14]. Pemodelan dibangun berdasarkan posisi Double Support Phase (DSP) robot humanoid dua kaki yang menyentuh tanah. Selama Satu Tahap Dukungan (SSP) satu kaki robot pada posisi udara. Persamaan gerak Lagrange dapat ditulis dalam bentuk:

$\mathrm{D}(\mathrm{q}) \ddot{q}+\mathrm{H}(\mathrm{q}, \dot{q}) \dot{q}+\mathrm{G}(\mathrm{q}, \dot{q})=\mathrm{B} \tau$

Dimana :

$\mathrm{D}(\theta)$ : inersia matrik

$H(\theta, \theta)$ : coriolis dan centripetal

$G(\theta)$ : gravitasi

Pada titik koordinat referensi

$X_{t}=X_{S}+l_{1} \cos \theta_{1}+l_{2} \cos \theta_{2}+l_{3} \cos \theta_{3}+l_{4} \cos \theta_{4}+l_{5} \cos \theta_{5}+l_{6} \cos \theta_{6}+l_{7} \cos \theta_{7}$

$Y_{t}=Y_{s}+l_{1} \sin \theta_{1}+l_{2} \sin \theta_{2}+l_{3} \sin \theta_{3}+l_{4} \sin \theta_{4}+l_{5} \sin \theta_{5}+l_{6} \sin \theta_{6}+l_{7} \sin \theta_{7}$

Dengan pendekatan langrang secara umum dapat dituliskan

$\frac{d}{d t}\left(\frac{\partial L}{\partial q_{i}}\right)-\frac{\partial L}{\partial \phi_{i}}=\tau_{i}$

Dengan

$\mathrm{L}=\mathrm{E}_{\mathrm{k}}-\mathrm{E}_{\mathrm{p}}$

$E_{\mathrm{k}}=$ energi kinetik

$\mathrm{E}_{\mathrm{p}}=$ energi potensial

$\mathrm{q}=$ Generalized coordinate

sebagai contoh, persamaan dinamik robot seperti dalam gambar akan kita peroleh melalui metode LE. Koordinat $\mathrm{P}(\mathrm{x}, \mathrm{y})$ memiliki sifat translasi (keliling) dan rotasi (pada sumbu putar) , maka tenaga kinetiknya

$E_{k}=\frac{1}{2} m v^{2}+\frac{1}{2} \mathrm{I} \theta^{2}$

$E_{p}=m \cdot g \cdot y_{c}$

Karena model robot memiliki 7 link, sehingga total energi kenetik dan energi potensial adalah sebagai berikut :

$\mathrm{E}_{\mathrm{k}}=\sum_{\mathrm{i}=\mathbb{1}} \cdot E_{k}$ 


$$
E_{k}=E_{k 1}+E_{k 2}+E_{k 1}+E_{k 4}+E_{k 5}+E_{k \bar{b}}+E_{k 7}
$$

$\mathrm{E}_{\mathrm{p}}=\sum_{\mathrm{i}=1}^{7} \cdot E_{p}$

$$
E_{p}=E_{p 1}+E_{p 2}+E_{p 3}+E_{p 4}+E_{p 5}+E_{p 6}+E_{p 7}
$$

Dimana

$\mathrm{g}=$ percepatan gravitasi $=9.81 \mathrm{~m} / \mathrm{s}^{2}$

$\mathrm{V}_{\mathrm{c}}=$ kecepatan pada setiap link $(\mathrm{m} / \mathrm{s})$

$\mathrm{Y}_{\mathrm{c}}=$ Pusat titik masa setiap link $(\mathrm{m})$,

$\theta=$ kecepatan sudut setiap link ( $\mathrm{rad} / \mathrm{s})$

Hubungan antara kinematik dan sudut $\theta_{i}, \mathrm{Y}_{\mathrm{ci}}, \mathrm{X}_{\mathrm{ci}}, \mathrm{V}_{\mathrm{ci}}$ adalah :

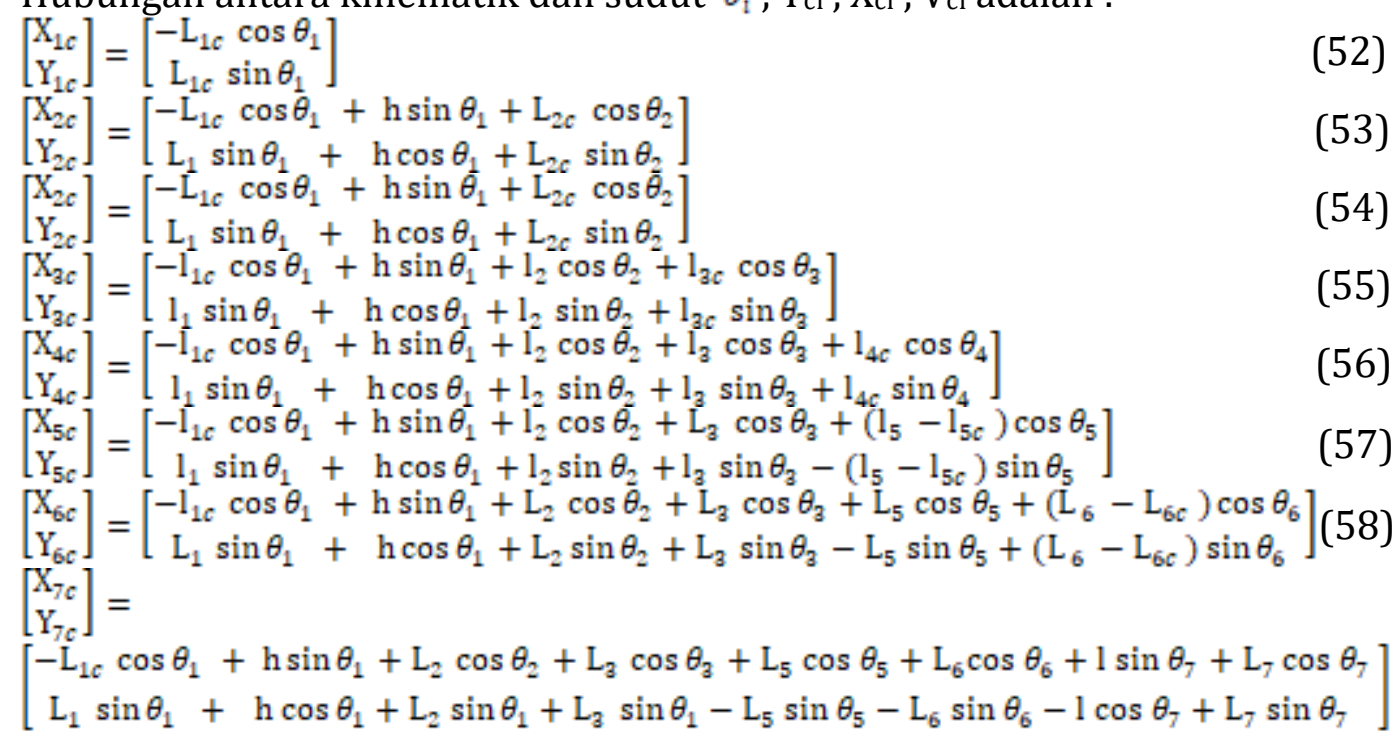

Dengan melakukan subtitusi persamaan (7) diatas maka akan didapatkan energi kinetik dan potensial pada setiap link.

Link 1 to link 7:

$E_{k 1}=\frac{1}{2} m_{1} v_{1}^{2}+\frac{1}{2} I_{1} \theta_{1}^{2}$

Untuk energi potensial didapatkan persamaan sebagai berikut

$\mathrm{P}_{1}=m_{1} g l_{10} \sin \dot{\theta}_{1}$

$\mathrm{P}_{2}=m_{2} g l_{1} \sin \hat{\theta}_{1}+m_{2} g h \cos \hat{\theta}_{1}+m_{2} g l_{2 e} \sin \hat{\theta}_{2}$

$\mathrm{P}_{3}=m_{2} g l_{1} \sin \hat{\theta}_{1}+m_{2} g h \cos \hat{\theta}_{1}+m_{2} g l_{2} \sin \hat{\theta}_{2}+m_{a} g l_{a c} \sin \hat{\theta}_{3}$

$\mathrm{P}_{4}=m_{4} g l_{1} \sin \theta_{1}+m_{4} g h \cos \theta_{1}+m_{4} g l_{2} \sin \theta_{2}+m_{4} g l_{2} \sin \theta_{2}+m_{4} g l_{4 \varepsilon} \sin \theta_{4}$

$P_{5}=m_{5} g l_{1} \sin \dot{\theta}_{1}+m_{5} g h \cos \dot{\theta}_{1}+m_{5} g l_{2} \sin \theta_{2}+m_{5} g l_{2} \sin \theta_{2}-m_{5} g l_{5} \sin \theta_{5}+m_{5} g l_{50} \sin \theta_{5}$ (65)

$\mathrm{P}_{6}=m_{6} g l_{1} \sin \theta_{1}+m_{6} g h \cos \theta_{1}+m_{6} g l_{2} \sin \theta_{2}+m_{6} g l_{2} \sin \theta_{3}-m_{6} g l_{5} \sin \theta_{5}-m_{5} g l_{6}$ $\sin \theta_{6}+m_{6} g l_{66} \sin \theta_{6}$

$\mathrm{P}_{7}=m_{7} g l_{1} \sin \theta_{1}+m_{7} g h \cos \theta_{1}+m_{7} g l_{2} \sin \theta_{2}+m_{7} g l_{3} \sin \theta_{2}-m_{7} g l_{5} \sin \theta_{5}-m_{7} g l_{5}$ $\sin \theta_{6}+m_{7} g k \cos \theta_{7}+m_{7} g l_{70} \sin \theta_{7}$

Sehingga dapat disederhanakan dengan matrik sebagai berikut. 
$D(q)=\left[\begin{array}{l}D_{11} D_{21} D_{31} D_{41} D_{51} D_{61} D_{71} \\ D_{12} D_{22} D_{32} D_{42} D_{52} D_{62} D_{72} \\ D_{13} D_{23} D_{23} D_{43} D_{53} D_{63} D_{73} \\ D_{14} D_{24} D_{34} D_{44} D_{54} D_{64} D_{74} \\ D_{15} D_{25} D_{35} D_{45} D_{55} D_{56} D_{75} \\ D_{16} D_{26} D_{36} D_{46} D_{56} D_{66} D_{76} \\ D_{17} D_{27} D_{37} D_{47} D_{57} D_{67} D_{77}\end{array}\right]$

$H(q)=\left[\begin{array}{l}H_{11} H_{21} H_{91} H_{41} H_{51} H_{61} H_{71} \\ H_{12} H_{22} H_{92} H_{42} H_{52} H_{62} H_{72} \\ H_{13} H_{23} H_{33} H_{43} H_{53} H_{63} H_{79} \\ H_{14} H_{24} H_{24} H_{44} H_{54} H_{64} H_{74} \\ H_{15} H_{25} H_{25} H_{45} H_{55} H_{65} H_{75} \\ H_{16} H_{26} H_{96} H_{46} H_{56} H_{66} H_{76} \\ H_{17} H_{27} H_{37} H_{47} H_{57} H_{67} H_{77}\end{array}\right]$

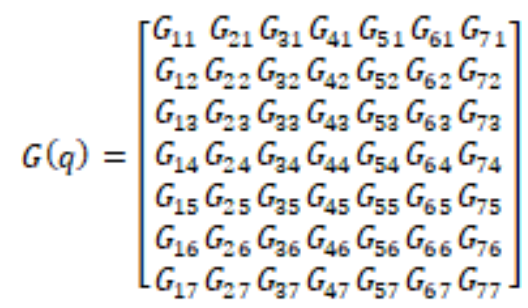

\subsection{Pengendali Keseimbangan}

Pada sistem ini menggunakan kendali PI (proporsional-Integral). Dimana kendali PI digunakan untuk menegendalikan keseimbangan dari seluruh badan robot agar tidak jatuh. Lapisan pertama dari kontrol loop tertutup adalah pengontrol bersama seluruh aktuator. Pada lapisan pertama ini telah dilakukan dengan menggunakan servo sebagai aktuator dari seri Dynamixel. Aktuator servo dynamixel telah memiliki kontrol internal dengan menggunakan pengontrol PID untuk mengatur posisi sudut dengan kecepatan sudut yang diinginkan. Kendali PI akan melacak pergerekan dari seluruh tubuh robot selama berjalan diatas tangga [15]. Setiap pose dan posisi robot saat naik tangga akan mempengaruhi keseimbangan. Untuk mengurangi gangguan (gesekan, brackless, dan sebagainya). Untuk mengkompensasi gangguan (gravitasi, gesekan, dan sebagainya), maka digunakan koreksi gangguan. Sehingga dilakukan pendekatan dengan pendulum terbalik. Kontroler PI melacak posisi dan pose robot selama menaiki tangga. Sendi pinggul memiliki pengaruh besar dalam KMEI dan robot humanoid lainnya. Ketika robot humanoid berada dalam kondisi SSP, sambungan pinggul dengan arah gulungan akan bekerja keras untuk memegang bagian lain seperti bagian batang dan bagian kaki lainnya. Kerja keras ini menyebabkan sistem mekanik robot humanoid dalam kondisi kritis. Kondisi kritis adalah kondisi tikungan. Karena itu, sistem kontrol akan diterapkan untuk memecahkan atau mengurangi masalah mekanis ini (masalah bending). Sistem kontrol ini akan fokus pada sendi pinggul dengan arah gulungan. Idenya adalah menempatkan sensor eksternal untuk merasakan derajat lentur dan mencoba mendorong bagian lentur hingga mencapai 
referensi posisi. Tindakan mendorong (sistem kontrol) dapat dilakukan dengan menggunakan pengontrol PI dari pengontrol PID. Diagram sistem kontrol pengendali PI yang diterapkan dapat dilihat pada Gambar 4. di bawah ini:

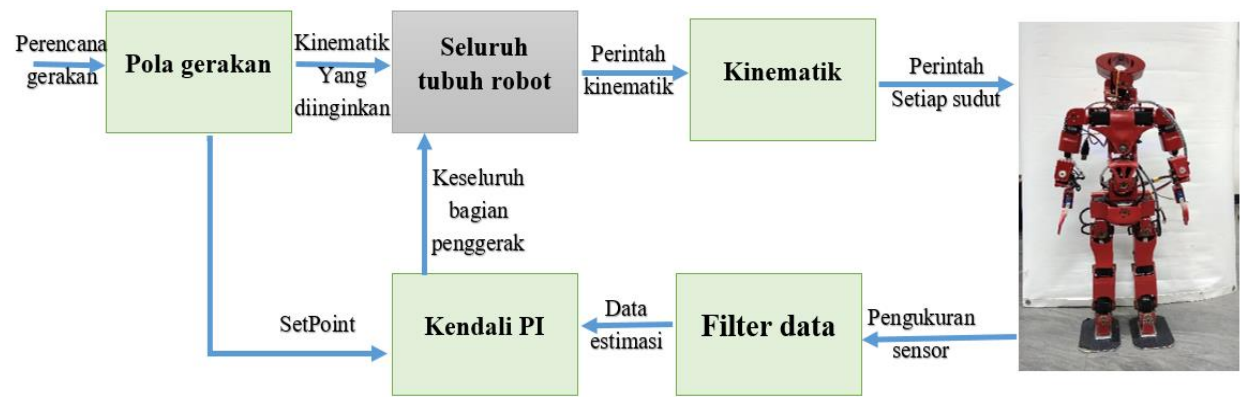

Gambar 4. Diagram kontrol naik tangga untuk keseimbangan

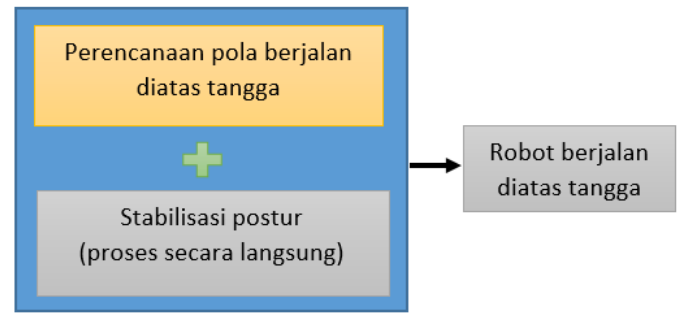

Gambar 5. Struktur Kontrol dasar dari robot berjalan diatas tangga

$$
y(t)=K_{p} e(t)+K_{i} \int_{0}^{t} e(\tau) d \tau
$$

Dimana $K_{p}$ merupakan konstanta proporsional dan e merupalan error koreksi dari sudut dan $K_{i}$ merupakan kosntanta integral. Dimana error menunjukkan kesalahan, vektor perintah posisi dari model dinamis masingmasing sudut, dan vektor respons posisi, masing-masing. Pada kendali konvensional ini akan melakukan kompensasi terhadap massa yang ditimbulkan akibat gerakan dinamis robot saat berjalan diatas tangga. Pada Gambar 5. tersebut robot dapat berjalan dengan adalanya pola dan stabilisasi postur tubuh robot. Pada stabilisasi postur ini akan berjalan dengan baik jika gerakan dinamis dapat dikendalikan dengan baik pula [16]. Kriteria stabil pada gerak dinamis robot dapat diukur dengan respon dan gerakan pada tubuh robot yang masuk pada area stabil. Jika keluar pada area stabil atau pada kondisi kritis maka kontrol akan mengendalikan gerak seluruh tubuh agar masuk kembali pada area stabil sehingga robot tidak jatuh saat melakukan gerakan yang khususnya naik tangga.

\section{HASIL DAN PEMBAHASAN}

Pada hasil simulasi naik tangga dengan 33 derajat kebebasan untuk memverifikasi algoritma yang digunakan. Dengan parameter sebagai berikut: 
Tabel 1: Parameter berjalan diatas tangga

\begin{tabular}{ll}
\hline Parameter & Nilai \\
\hline Panjang langkah & $0.15 \mathrm{~m}$ \\
Tinggi tangga & $0.04 \mathrm{~m}$ \\
Kecepatan naik tangga & $2.5 \mathrm{sec} / \mathrm{step}$ \\
Tinggi robot & $0.6 \mathrm{~cm}$ \\
\hline
\end{tabular}

KMEI robot Gambar 3. dirancang dan dibangun sebagai platform penelitian untuk menyelidiki gerakan naik tangga robot humanoid. Meskipun KMEI memiliki ukuran kecil dan ringan, KMEI masih memiliki konfigurasi sendi yang kompleks sebagai tubuh manusia dan dapat merealisasikan aktivitas yang menyulitkan. Gambar 3 adalah desain akhir dari konfigurasi bersama KMEI. Tabel 1 mencantumkan spesifikasi KMEI:
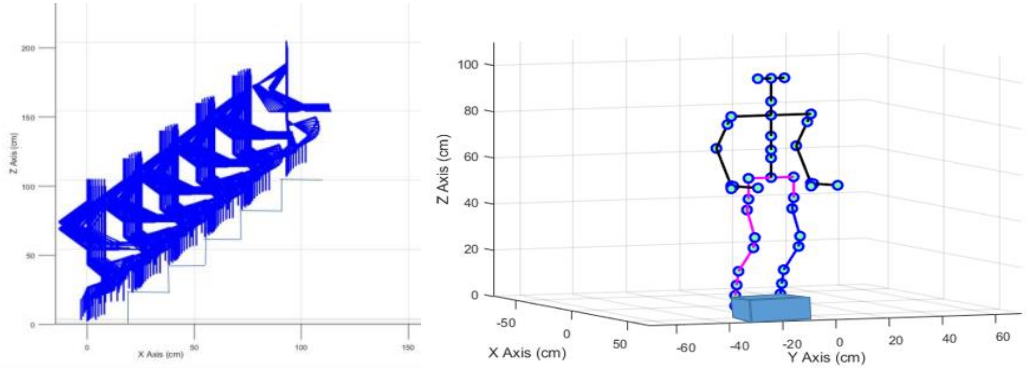

Gambar 6. Analisis seluruh tubuh selama berjalan diatas tangga

Kiprah Panjat Tangga dapat dibagi menjadi urutan langkah. Di bagian ini jelaskan tentang percobaan menggunakan 8x langkah berjalan di tangga. Selama gerak berjalan di tangga, Gambar 6. menunjukkan vektor posisi dan sambungan sudut. Gambar 6. menjelaskan penerapan analisis seluruh tubuh selama gerakan naik tangga. Pada kondisi satu kaki maka akan menjadi tumpuan seluruh tubuh dan kestabilan diuji pada kondisi ini. Perubahan titik akhir tubuh ini dapat terlihat saat robot bergerak dengan perhitungan dinamis dan posisi masing masing penggerak. Pada simulasi ini dengan memenuhi syarat kondisi robot berjalan satu kaki dan dua kaki. Dimana pada kaki satu akan terlihat membentuk pola saat naik tangga. Kondisi pertama dan kondisi kedua (kondisi kombinasi) tergantung pada kapan kaki kanan dan kiri menjadi basis pendukung. Hasil ketinggian COG dan ZMP dari berjalan di tanah dengan metode konvensional dan di tangga dengan metode yang diusulkan ditunjukkan pada Gambar 7. Terlihat bahwa pada tangga maka amplitudo ayunan kaki mengalami kenaikan setinggi tangga yang dilewati oleh robot. 

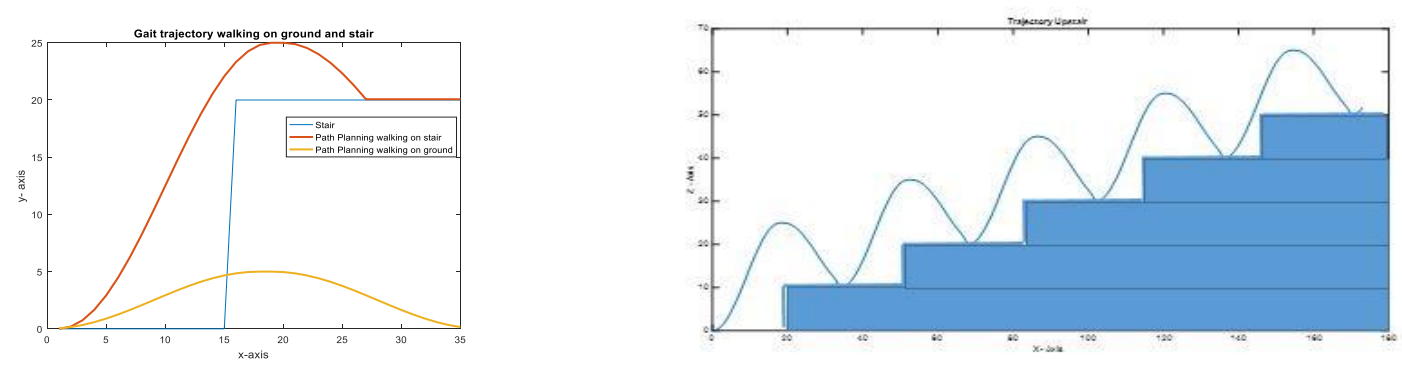

Gambar 7. Analisis pola step kaki ketika menaiki tangga

Berjalan di tangga gerak dibagi menjadi 8 langkah yaitu:

a. Langkah A (postur lurus): Pada posisi DSP, pose robot berdiri seperti default. Kaki dan lengan memiliki vektor posisi asal yang berbeda. Jadi, pada gambar percobaan, lengan dan kaki memiliki postur membungkuk.

b. Langkah B (mengangkat kaki): pada langkah kedua dengan posisi SSP, kaki robot ditekuk. Dalam input kartesius, input pada sumbu $\mathrm{Z}$ berubah dan input pada sumbu X tidak berubah. Seperti Gambar. 8 robot melakukan satu kaki.

c. Langkah C (mengangkat kaki dan mengayunkan kaki): pada langkah ketiga, kaki robot memiliki postur yang serupa. Namun, input pada sumbu Y berubah dan input pada sumbu X-Z tidak berubah. Jika dilihat dalam percobaan Gbr. 8, robot dengan postur serupa bergerak ke arah kiri.

d. Langkah D (posisi naik dan maju): pada langkah keempat, kaki robot bergerak maju ke tahap berikutnya di tangga. Tapi, input pada sumbu X berubah. Jadi, robot dengan postur serupa bergerak ke arah depan.

e. Langkah E (posisi naik dan maju): pada langkah kelima, tubuh robot dengan postur serupa bergerak ke arah yang benar (kiri ke kanan). Input pada sumbu X berubah dan input pada sumbu Y-Z tidak berubah.

f. Langkah F (posisi naik dan maju): langkah keenam adalah ketika tubuh robot dengan postur yang sama bergerak ke arah belakang (maju ke belakang). Input pada sumbu Y berubah dan input pada sumbu Z-X tidak berubah.

g. Langkah G (langkah naik postur ke bawah): langkah ketujuh adalah ketika tubuh robot mengubah postur di area stabilitas.

h. Langkah H (postur berdiri): delapan langkah adalah posisi DSP, pose robot berdiri seperti default. 

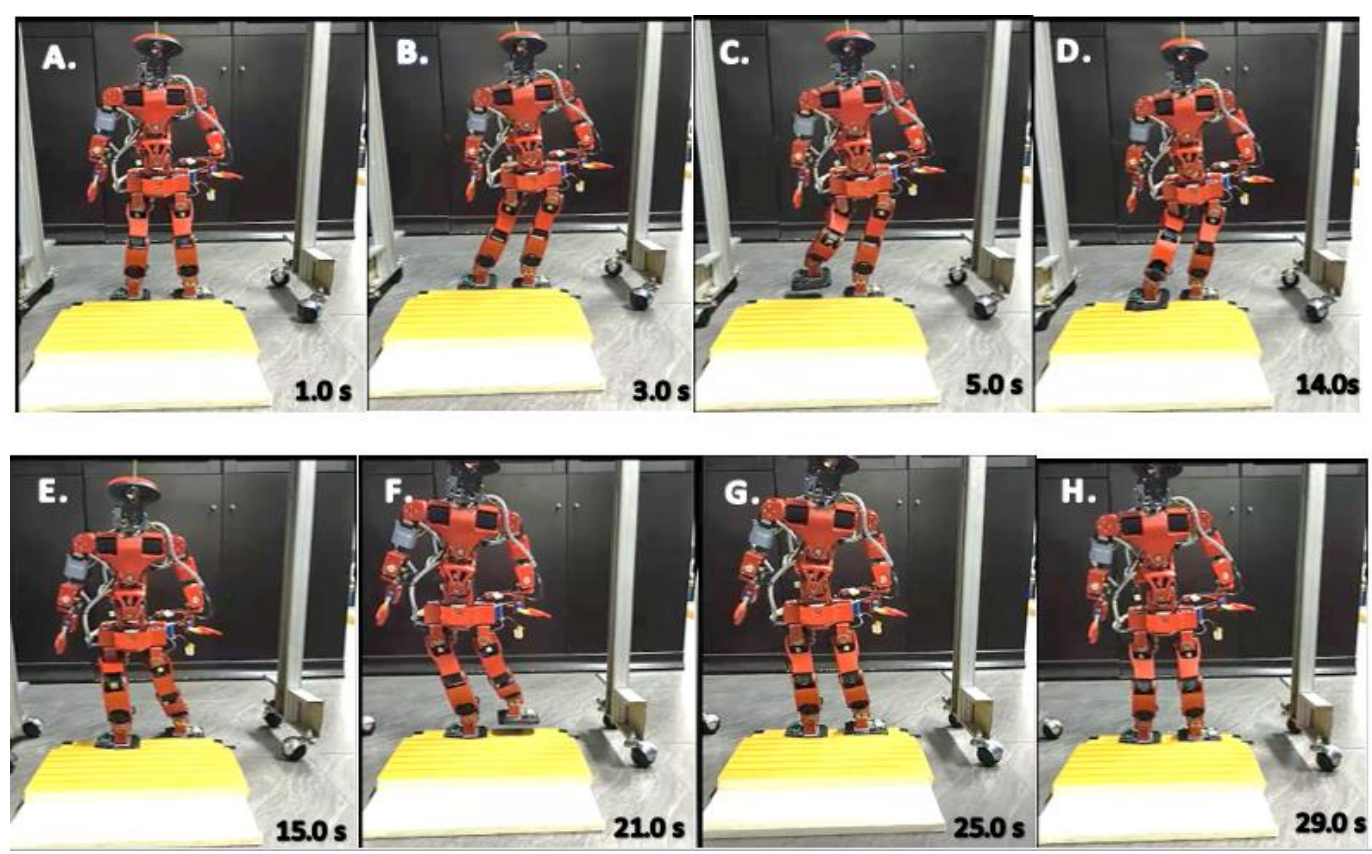

Gambar 8. Siklus ketika naik tangga tampak depan

Dalam percobaan ini, lebar tangga ditetapkan 0,35 $\mathrm{m}$, dan tinggi tangga ditetapkan 0,04 m. Dengan melakukan validitas metode yang diusulkan dikonfirmasi pada robot. Cuplikan dari berjalan di tangga ditunjukkan pada gambar 8. Dari cuplikan tersebut terdapat hasil respon pada gambar 9. Pengendali untuk seluruh tubuh robot menggunakan kendali PI dengan respon perubahan sudut ketika naik diatas tangga. Pada bagian paha arah pitch terlihat bahwa ketika menapaki tangga akan terlihat menukuk dengan sudut sebesar $100^{\circ}$, ketika kaki kiri mulai naik maka kaki kiri menekuk kebelakang telebih dahulu dengan sudut sebesar $40^{\circ}$.

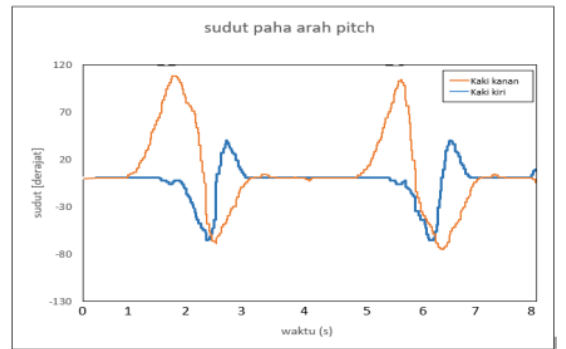

(A)

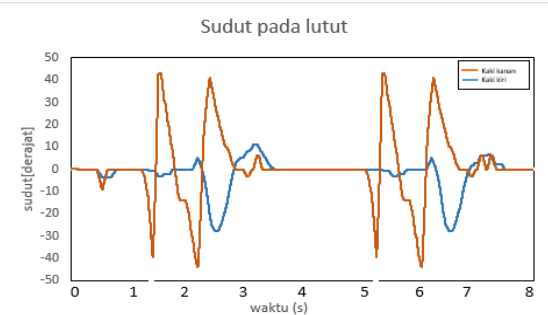

(C)

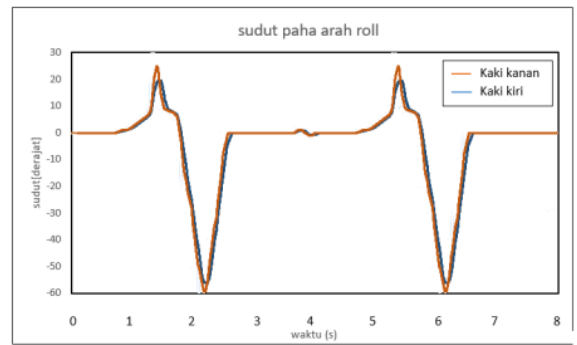

(B)

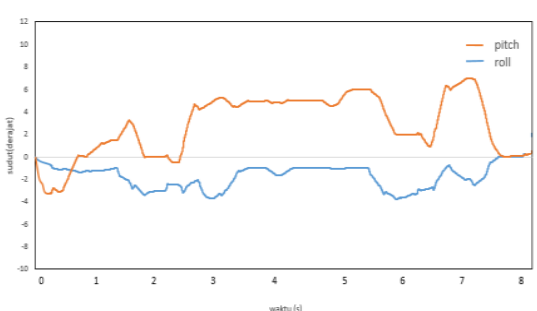

(D)

Gambar 9. Respon sudut kaki ketika naik tangga 
Hasil respon pada paha bagian roll memiliki siklus yang sama antara kaki kanan dan kaki kiri pada gambar 9B. Gerakan yang sama ini menunjukkan bahwa semua penggerak sinkron menjadi satu. Dimana membentuk sudut $25^{0}$ ketika salah satu berada pada tangga selanjutnya seperti pada gambar 8D. Ketika mulai berada pada posisi tangga yang sama maka sudut paha arah roll akan membentuk sudut sebesar $40^{\circ}$ seperti pada gambar 8E. Pada gambar tersebut nilai lebih besar karena perpindahan pusat massa dengan tumpuan kaki satu menuju tangga selanjutnya. Hasil respon bagian lutut pada gambar 9C memiliki siklus yang rapat karena terlihat bahwa perubahan tinggi tangga akan berpengaruh pada lutut seperti pada gambar 8C. Dan lutut sebagai tumpuan sebagai gerakan yang dinamis pada seluruh tubuh robot. Maka akan membentuk sudut $40^{\circ}$ ketika naik tangga. Perubahan gerak secara dinamis akan mengakibatkan siklus berbentuk sinus.

\section{SIMPULAN}

Kendali PI telah diterapkan pada robot untuk mejaga keseimbangan ketika berjalan naik diatas tangga. Pada hasil percobaan ini di hasilkan respon gelombang sinus yang merupakan ciri khas dari robot berjalan dan terlihat pula perbedaan sudut yang lebih besar ketika naik tangga. Perbedaan sudut antara kaki kanan dan kaki kiri ketika naik tangga menandakan bahwa robot melakukan gerakan dinamis agar robot tidak terjatuh dengan memperhitungkan titik nol massa. Sehingga perpindahan pusat massa ini yang akan menjadikan kompensasi gerakan selanjutnya. Pada siklus ini berdiri dengan satu kaki dapat dlihat dengan hasil respon yang memiliki sudut $100^{\circ}$ pada paha arah pitch yang dipengaruhi oleh ketinggian tangga itu sendiri. Dengan adanya ketinggian tangga maka robot harus melakukan gerakan menaiki tangga dengan keseimbangan satu kaki sehingga pada siklus ini terlihat adanya gaya keatas yang diberikan pada tubuh robot.

\section{DAFTAR PUSTAKA}

[1] Shukla, Y. M., Tamba, A., Pandey, S., \& Sharma, P. (2014). A review and scope of humanoid robotics. no. March, 28-29.

[2] Abror, Barorotul, and Dadet Pramadihanto. "Dance motion pattern planning for $\mathbf{K}$. Mei as dancing humanoid robot", 2017 International Conference on Robotics, Biomimetics, and Intelligent Computational Systems (Robionetics). IEEE, 2017.

[3] Kwon, Taesoo, and Jessica K. Hodgins. "Control Systems for Human Running using an Inverted Pendulum Model and a Reference Motion Capture Sequence", Symposium on Computer Animation, 2010.

[4] Liu, Jing, and Oliver Urbann. "Bipedal walking with dynamic balance that involves three-dimensional upper body motion", Robotics and Autonomous Systems 77, 39-54, 2016.

[5] Brasseur, C., Sherikov, A., Collette, C., Dimitrov, D., \& Wieber, P. B. "A robust linear MPC approach to online generation of 3D biped walking motion", In 2015 IEEE-RAS 15th International Conference on Humanoid Robots (Humanoids) (pp. 595-601). IEEE. 2015. 
[6] Shahrokhshahi, Ahmadreza, et al. "Optimal Stair Climbing Pattern Generation for Humanoids Using Virtual Slope and Distributed Mass Model ", Journal of Intelligent \& Robotic Systems 94.1, 43-59, 2019.

[7] Liu, Chengju, et al. "Active Balance Control of Humanoid Locomotion Based on Foot Position Compensation", Journal of Bionic Engineering 17.1, 134-147, 2020.

[8] Caron, Stéphane, Abderrahmane Kheddar, and Olivier Tempier. "Stair climbing stabilization of the HRP-4 humanoid robot using whole-body admittance control ",2019 International Conference on Robotics and Automation (ICRA). IEEE, 2019.

[9] Żurawska, Magdalena Sylwia, Maksymilian Szumowski, and Teresa Zielińska. "Reconfigurable double inverted pendulum applied to the modelling of human robot motion ", Journal of Automation Mobile Robotics and Intelligent Systems 11, 2017.

[10] Guan, Yishen, et al. "On robotic trajectory planning using polynomial interpolations", 2005 IEEE International Conference on Robotics and Biomimetics-ROBIO. IEEE, 2005.

[11] Kim, Jung-Yup, Ill-Woo Park, and Jun-Ho Oh. "Realization of dynamic stair climbing for biped humanoid robot using force/torque sensors", Journal of Intelligent and Robotic Systems 56.4, 2009.

[12] Jazar, Reza N. Theory of applied robotics: kinematics, dynamics, and control. Springer Science \& Business Media, 2010.

[13] Nenchev, Dragomir N., Atsushi Konno, and Teppei Tsujita. Humanoid robots: Modeling and control. Butterworth-Heinemann, 2018.

[14] Hooshang, and Bostwick Wyman. "Modeling and control of constrained dynamic systems with application to biped locomotion in the frontal plane", IEEE Transactions on Automatic Control 24.4, 526-535, 1979.

[15] Mandava, Ravi Kumar, and Pandu Ranga Vundavilli. "Near optimal PID controllers for the biped robot while walking on uneven terrains", International Journal of Automation and Computing 15.6, : 689706, 2018.

[16] Liu, Chengju, Jing Ning, and Qijun Chen. "Dynamic walking control of humanoid robots combining linear inverted pendulum mode with parameter optimization", International Journal of Advanced Robotic Systems 15.1, 1729881417749672, 2018. 